\title{
DIMETHOATE HEPATOTOXICITY IN MICE EXPOSED TO CHRONIC INTOXICATION
}

\author{
Nashwa Mohamad Mohamad Shalaby and Abeer Ramzy Hussieny \\ Departments of Forensic Medicine and Clinical Toxicology; Faculty of Medicine; Zagazig \\ University.
}

\begin{abstract}
Background: Because pesticides play an important role in agriculture field, and their use has increased, the evaluation of their toxic effects is of major concern to public health. Aim: The aim of this work was to study the propensity of dimethoate (DM) to cause hepatic function disturbance in mice. Material and Methods: Dimethoate was administered orally at doses of $(20 \mathrm{mg} / \mathrm{kg}$ body weight $)$ dissolved in 1 $\mathrm{ml}$ corn oil [1/20 of the LD50 $(380 \mathrm{mg} / \mathrm{kg})]$ once daily for 14 weeks. Biochemical parameters in serum were studied: aminotransferases (ALT and AST), alkaline phosphatase (ALP), total proteins and albumin. Liver will be examined by light and electron microscope to evaluate histopathological changes. Results: Our results indicated that: the levels of the ALT and AST, ALP as well as bilirubin, in the serum of treated rabbits showed highly significant $(\mathrm{P}<0.0001)$ increase compared to control animals, whereas either, total protein, and albumin were highly significantly decreased $(\mathrm{P}<0.0001)$.Light microscopic examination of the hepatic tissue in dimethoate treated group showed congested portal vein, dilated bile duct, hepatocytes with vacuolated cytoplasm and deeply stained shrunken nuclei and hemorrhage. While electron microscope of the same group showed areas of hemorrhage, apoptotic nucleus and necrotic areas. In conclusion: Our study demonstrated that administration of DM orally at doses of $(20 \mathrm{mg} / \mathrm{kg}$ body weight) [1/20 of the LD50] for 14 weeks induced disturbance in the liver function .It is recommended to do Further investigations to prove the implication of oxidative stress in liver function disturbance and study the role of antioxidant in its limitation.
\end{abstract}

Key words: Dimethoate, liver, organophosphates.

\section{INTRODUCTION}

Dimethoate (DM) is an organophosphates insecticide which acts by interfering with the activities of cholinesterase (Gore, 2001).

Dimethoate is used to kill both mites and insects. It is also used as a residual wall spray in farm buildings for house flies and has been administered to livestock for control of botflies. It is available in aerosol spray; dust, and emulsifiable concentrate (Mirajkar and Pope, 2005).

The oral LD50 for DM in rats is 60 to $387 \mathrm{mg} / \mathrm{kg}$ (Dreher, 2001a), 60 $\mathrm{mg} / \mathrm{kg}$ in mice, $400 \mathrm{mg} / \mathrm{kg}$ in dogs, 200 $\mathrm{mg} / \mathrm{kg}$ in hamsters, $300 \mathrm{mg} / \mathrm{kg}$ in rabbits, $350 \mathrm{mg} / \mathrm{kg}$ in guinea pigs, and $100 \mathrm{mg} / \mathrm{kg}$ in cats (Meister, 1992). The dermal LD50 in rabbits is $1,000 \mathrm{mg} / \mathrm{kg}$, and $353 \mathrm{mg} / \mathrm{kg}$ in rats. A dermal LD50 of greater than $2,000 \mathrm{mg} / \mathrm{kg}$ in rats has also been reported (Dreher, 2001b \& Dreher, 2001c).

The extensive use of dimethoate carries a health hazard to animals and humans due to its persistence in soil and crops (WHO/IPCS, 1996). Majority of population is exposed to lower doses of dimethoate via food, contaminated 
drinking water, or by application of household insecticides containing dimethoate (Sharma et al., 2005).

Repeated or prolonged exposure to organophosphates may result in many effects as acute exposure, including the delayed symptoms. Workers repeatedly exposed to DM reported impaired memory, disorientation, depressions, irritability, confusion, headache, speech difficulties, delayed reaction times, nightmares, sleepwalking and drowsiness or insomnia. Also, influenzalike condition with headache, nausea, weakness, loss of appetite, and malaise has also been reported (Ogutcu et al., 2008).

Dimethoate affects the functions of multiple organs including liver. Dimethoate was reported to alter the level of the marker parameters related to the liver in rats and mice (Chatterjea and Shinde, 2005; Attia and Nasr, 2009; Saafi et al., 2011 and Khan et al., 2013).

Organophosphorus insecticides affect other organs (Betrosianet al., 1995; and Senanayke1998), specially CNS, (Desi et al., 1998; and Lengylet al., 2005), kidney (Kossmannet al., 1997), and pancreas (Hagar and Fahmy 2002; Kamath and Rajini 2007; Kamath et al. 2008).

Also immune-toxic effect were reported (Institóris et al. 1995, 1999; Undeger et al. 2000) with several adverse effects in the reproductive system of male and female mice (Mahadevaswami and Kaliwal 2002, 2004; Farag et al. 2007; Astiz et al. 2009).

Dimethoate was reported to cause both benign and malignant neoplasms of the liver, endocrine organs, and lymphatic system (Reuber 1984), besides being considered as human teratogen and mutagen (Hallenbeck and Cunningham-Burns, 1985).

The main toxic effect of OP pesticides is the inhibition of acetylcholinesterase (De-Bleecker et al., 1993; and Dongren et al., 1999). Also OP compounds induce oxidative stress in humans (Ranjbar et al. 2002) and animals (Debnath and Mandal 2000), leading to different types of DNA lesions including single- and double DNA strand breaks, cross links,

Chromosomal aberrations and DNA base oxidation in toadfish lymphocytes (Lopes et al. 1998; Twigg et al. 1998; Ellingham et al., 1986). And it was also reported to increase the incidence of numerical but not structural chromosomal aberration in male Wistar rats (Undeger et al. 2000; Nehéz and Dési 1996). Other studies done by Gillot-Delhalle et al. (1983) founded that DM was non-mutagenic.

So the aim of the present study is to investigate the hepatotoxic effect of diemethoate either by biochemical changes or by histopathological lesions.

\section{MATERIAL\& METHODS}

Material

\section{[A] Chemicals}

Dimethoate: It was obtained from Sigma, Aldrich in Germany imported by Cairo Chemical Company.

Corn oil was used for preparing suspensions of DM.

\section{[B] Animals}

This study was carried out on 30 adult male albino rats, their weights ranged from 120-150 gms, they were obtained from animal's house, Faculty of Veterinary Medicine, Zagazig University. Before commencing the experimentation, all animals were subjected to 14 days period of passive preliminaries in order to be adapting to 
the new environment, to ascertain their physical wellbeing and to exclude any diseased animals. The experimental procedures were carried out according to the National Institute of Health Guidelines for Animal Care.

\section{[C]Experimental Design:}

Animals were divided into 3 groups each of 10 rats as follow:

Group I (negative control group):-

These rats will receive only regular diet and tap water for 14 weeks to measure the basic parameters.

\section{Group II (positive control group):-}

Each rat will be gavaged orally with $1 \mathrm{~mL}$ corn oil once daily for 14 weeks.

Group III (dimethoate treated group):-

These rats will be gavaged orally with dimethoate $(20 \mathrm{mg} / \mathrm{kg}$ body weight) dissolved in $1 \mathrm{ml}$ corn oil [1/20 of the LD50 (380 mg/kg)] (Kamath et al., 2008) once daily for 14 weeks.

Rats were weighed every week and the doses were adjusted according to the changes in the body weight.

\section{Methods:}

At the end of the experimental periods, rats of all groups were used to measure the following parameters.

\section{[A] Biochemical parameters}

After the experimental periods the animals were sacrificed, the blood was immediately collected and centrifuged to obtain serum which discarded and kept at $-21^{\circ} \mathrm{C}$ for the biochemical testes.

(1) Alanine- aminotransferase (ALT) and Aspartateaminotransferase (AST) Assay:

The estimation was carried out according to the method originally developed by (Reitman and Frankel 1957).

(2) Alkaline phosphatase Assay:
ALP was determined using a colorimetric method as described by (Kind and King 1954).

(3) Total Protein Assay:

The total protein was determined by Biuret method explained by (Tietz 1976)

\section{(4) Albumin Assay:}

Serum albumin was determined according to the method of (Doumaset al., 1971).

\section{(5) Bilirubin assay:}

The estimation was carried out according to the method originally developed by (Pearlman and lee, 1974).

[B] Tissue parameters:

Liver was immediately dissected out and grossly inspected to assess any gross abnormalities then washed with cold normal saline and used for histopathological study.

(1) Light microscope examination:

The liver was fixed in $10 \%$ formalin saline. After fixation, tissues were embedded in paraffin blocks and processed for the preparation of $5 \mathrm{u}$. thickness sections. These sections were subjected for Hematoxylin and Eosin stains (Horobin and Bancroft, 1998) and then examined by light microscope.

(2) Electron microscope

\section{examination:}

Immediately after dissection, minute specimens will be rinsed in $0.1 \mathrm{M}$ phosphate buffer $\mathrm{pH} 7.2$ (PB) to remove blood from the surface. Liver tissues greater than $2 \mathrm{~cm}$ long were minced into smaller pieces of approximately $3 \times 3$ $\mathrm{mm}$ and were fixed in 3 percent glutaraldehyde, buffered with phosphate buffer for 3 hours. It was rinsed twice with phosphate buffer for 10 minutes per rinse. The tissues were then fixed in 2 percent aqueous osmium tetroxide for 2 hrs and rinsed in 3 changes of distilled 
water for 10 minutes. Each dehydration was accomplished by immersion in a graded series of ethanol solutions of 25 , 50, 75, 95and 100 percent. Infiltration with propylene oxide and embedding with increasing concentrations of propylene oxide followed by dehydration were carried. Thin sections $(600 \mathrm{~nm})$ were obtained by use of Ultra microtome and were placed on a copper200 - mesh grid. They were stained with uranyl acetate and lead citrate and examined with GEOLTEM1010electron

(Goodhew et al., 2003).

Statistical analysis:

Data were analyzed by Statistical Package of Social Science (SPSS), software version 22.0 (SPSS Inc., 2013).

\section{RESULTS}

\section{I)-Biochemical parameters results:}

As regard the control groups (negative and positive control group): There was a non-significant difference between them as regard biochemical parameters (Tables 1).

So the negative control group was chosen to compare with the treated group (Dimethoate treated group). LD50 of Dimethoate resulted in a statistically high significant increase in the level of alanine - aminotransferase (ALT) aspartate - aminotransferase (AST) and alkaline phosphatase (ALP) in the serum of treated group, as compared to the control.
Total protein and albumin levels showed highly significant decrease in the serum of treated with Dimethoate as compared to control (Tables 2).

\section{II)-Histopathological changes:}

Macroscopic appearance showed non-significant changes in size or abnormal masses compared with the control groups. Cut sections were apparently normal.

Light Microscopic examination of the liver specimens in the control untreated group showed a normal histological picture. The central vein lies at the center of the lobule surrounded by the hepatocytes with strongly eosinophilic granulated cytoplasm, and distinct nuclei. In addition, between the strands of hepatocytes the hepatic sinusoids are exhibited as shown in (Fig.1).

While the liver of mice treated with dimethoate showed congestion portal vein(Fig.2), dilated bile duct , Hepatocytes with vacuolated cytoplasm and deeply stained shrunken nuclei (Fig.3) and liver hemorrhage (Fig.5 ),

Electron microscopic examination of the control group showed hepatocytes appeared with eu-chromatic nuclei containing prominent nucleoli. The cytoplasm contained numerous mitochondria, rough endoplasmic reticulum (Figs.5).While dimethoate treated group showed areas of hemorrhage, apoptotic nucleus and necrotic areas (Figs.6, 7). 
Table (1): the liver function tests for the negative control group (I) and corn oil group (II) group, unpaired t test (mean \pm SD).

\begin{tabular}{|c|c|c|c|c|}
\hline \multirow{2}{*}{ Group } & $\begin{array}{c}\text { Negative control } \\
\text { group(I) }\end{array}$ & $\begin{array}{c}\text { Corn oil treated } \\
\text { Group(II) }\end{array}$ & \multirow{2}{*}{ T } & P \\
\cline { 2 - 3 } & Mean \pm SD & Mean \pm SD & & \\
\hline AST & $14.11 \pm 3.49$ & $14.99 \pm 3.47$ & 0.5654 & $>0.05$ \\
\hline ALT & $25.2 \pm 3.40$ & $25.8 \pm 3.41$ & 0.3940 & $>0.05$ \\
\hline ALK & $95.6 \pm 2.6$ & $97.4 \pm 2.7$ & 1.5186 & $>0.05$ \\
\hline Total protien & $6.11 \pm 0.25$ & $6.15 \pm 0.23$ & 0.3724 & $>0.05$ \\
\hline Albumin & $3.72 \pm 0.16$ & $3.73 \pm 0.18$ & 0.1313 & $>0.05$ \\
\hline Globlin & $1.82 \pm 0.09$ & $1.83 \pm 0.11$ & 0.2225 & $>0.05$ \\
\hline Bilrubin & $1.60 \pm 0.05$ & $1.59 \pm 0.02$ & 0.5872 & $>0.05$ \\
\hline
\end{tabular}

Number of sacrificed rats for each group was 10 rats.

SD : Standard Deviation. $\quad$. $\quad$ p>0.05 : non-significant

Table (2): the liver function tests for the negative control group (I) and Dimethoate treated group, unpaired $t$ test (mean \pm SD).

\begin{tabular}{|c|c|c|c|c|}
\hline Group & $\begin{array}{c}\text { Negative control } \\
\operatorname{group}(I)\end{array}$ & $\begin{array}{c}\text { Dimethoatetreated } \\
\text { group(III) }\end{array}$ & & P \\
\hline Parameter & Mean \pm SD & Mean \pm SD & $\mathbf{T}$ & \\
\hline AST & $14.11 \pm 3.49$ & $118.24 \pm 1.49$ & 86.7744 & $<0.0001 * * *$ \\
\hline ALT & $25.2 \pm 3.40$ & $167.3 \pm 12.11$ & 35.7252 & $<0.0001 * * *$ \\
\hline ALK & $95.6 \pm 2.6$ & $119.7 \pm 4.22$ & 15.3755 & $<0.0001 * * *$ \\
\hline Total protien & $6.11 \pm 0.25$ & $4.2 \pm 0.19$ & 19.2351 & $<0.0001 * * *$ \\
\hline Albumin & $3.72 \pm 0.16$ & $2.33 \pm 0.07$ & 25.1689 & $<0.0001 * * *$ \\
\hline Globlin & $1.82 \pm 0.09$ & $1.64 \pm 0.03$ & 6.0000 & $<0.0001 * * *$ \\
\hline Bilrubin & $1.60 \pm 0.05$ & $1.85 \pm 0.06$ & 10.1222 & $<0.0001 * * *$ \\
\hline
\end{tabular}

Number of sacrificed rats for each group was 10 rats.

SD : Standard Deviation. $\quad * *$ : Highly-significant $(\mathbf{P}<0.001)$ 


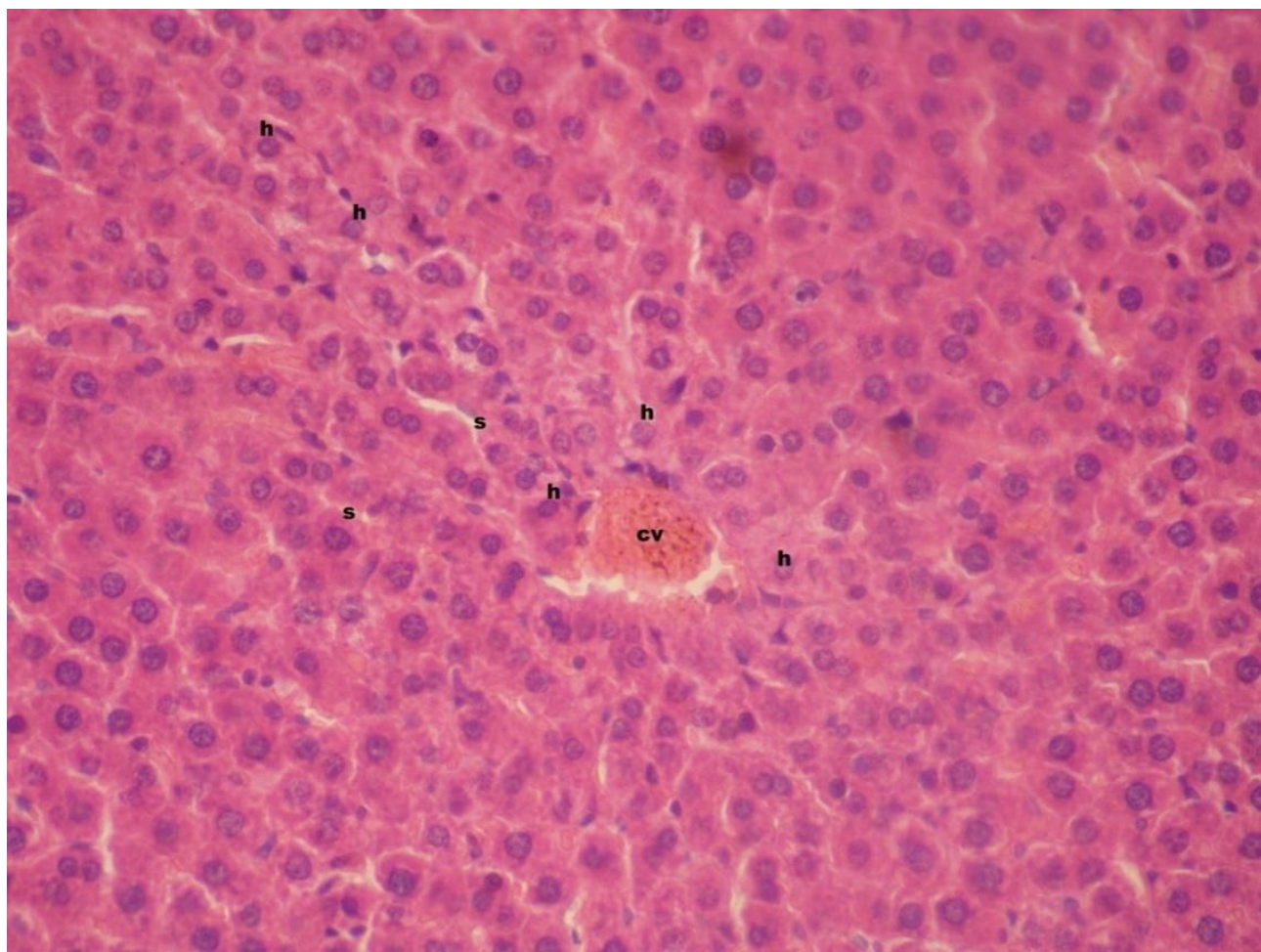

Figure (1): A photomicrograph of a section from the liver of a control group showing hepatocytes (h) arranged in plates radiating from the central vein (cv) and separated by blood sinusoids (s); hepatocytes are polygonal in shape, with central rounded vesicular nuclei and acidophilic cytoplasm.

(H\&E X 400)

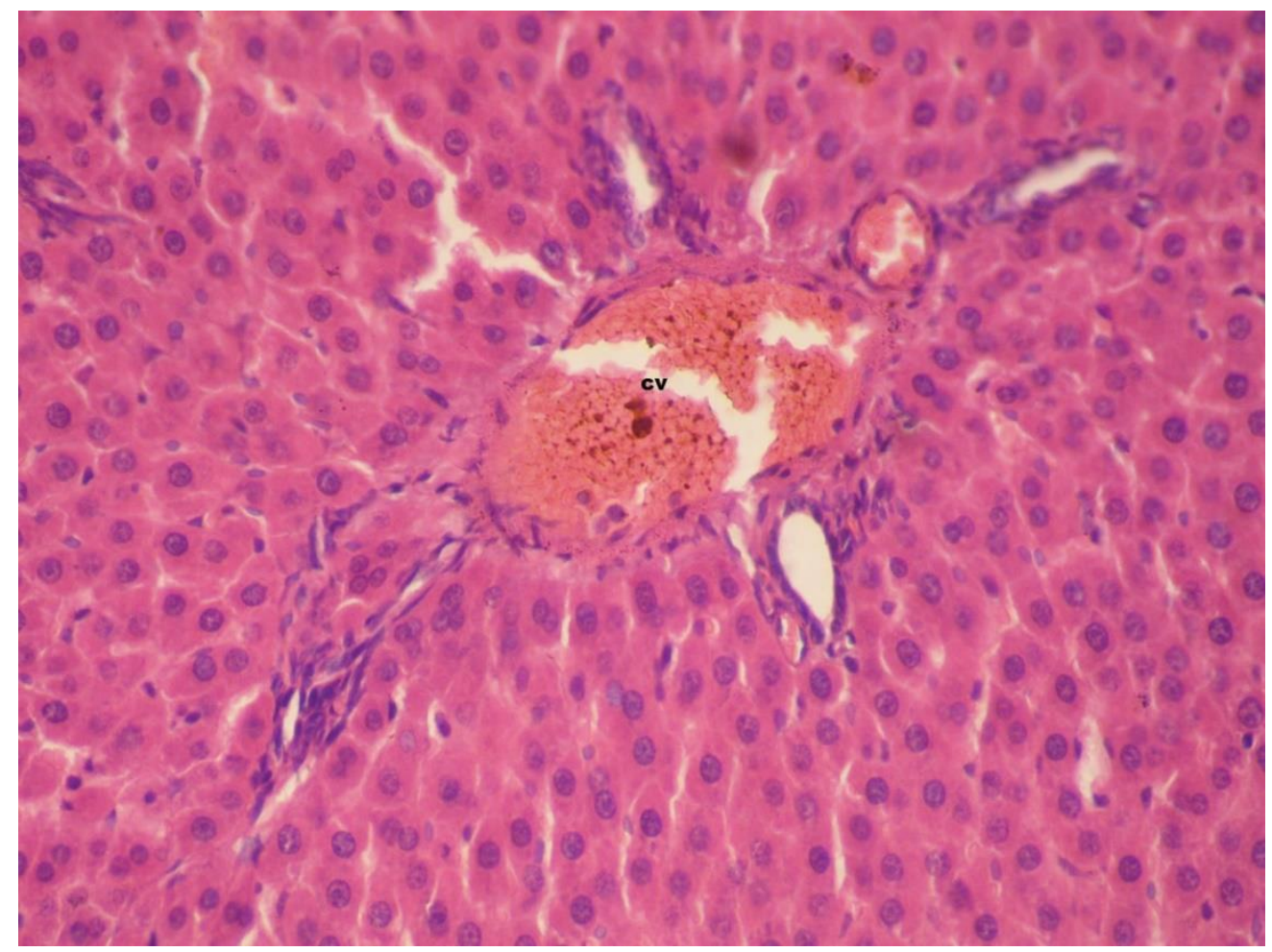

Figure (2): A photomicrograph of a section of liver of dimethoate treated group showing congested portal vein (cv).

(H\&E X 400) 


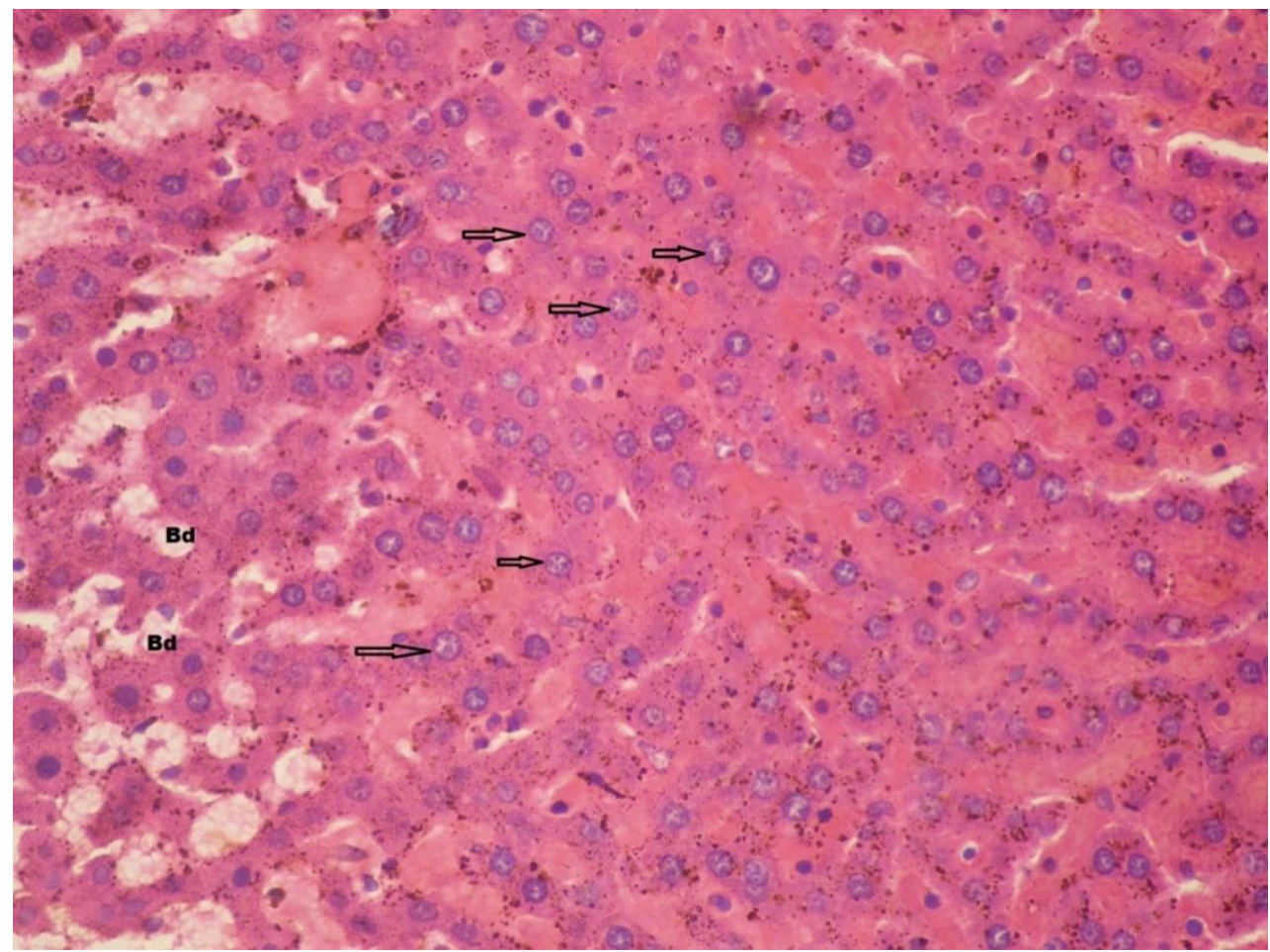

Figure (3): A photomicrograph of liver of dimethate treated group showing dilated bile duct (Bd). Hepatocytes (arrow) have vacuolated cytoplasm and deeply stained skrunken nuclei.

$(\mathbf{H} \& \mathbf{E} \times \mathbf{4 0 0})$

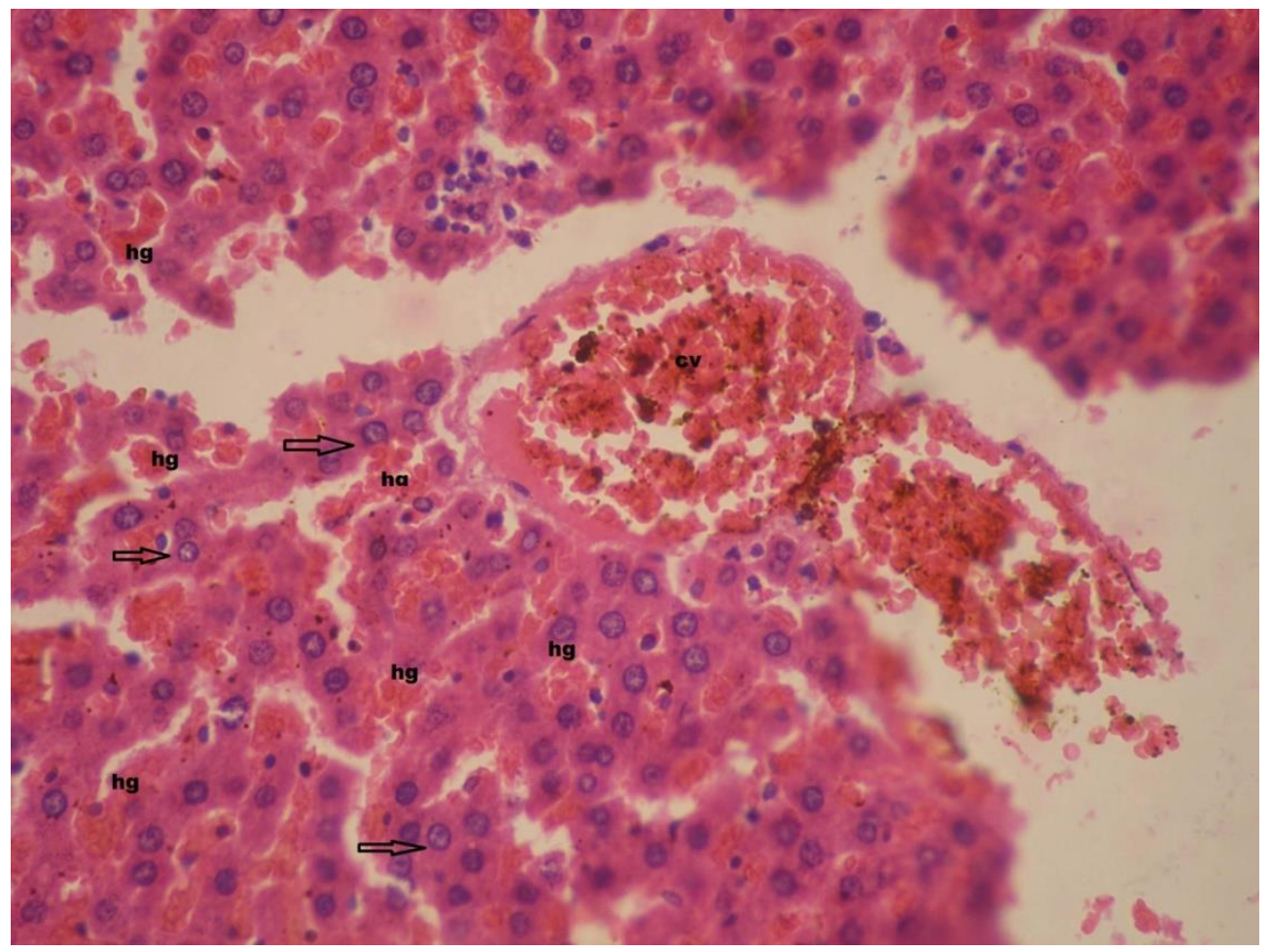

Figure (4): A photomicrograph of a section of liver of dimethate treated group showing congested portal vein (cpv) ,hepatocytes (arrow) have vacuolated cytoplasm and deeply stained skrunken nuclei, multiple areas of hgs in between cells (hg) .

(H\&E X 400) 


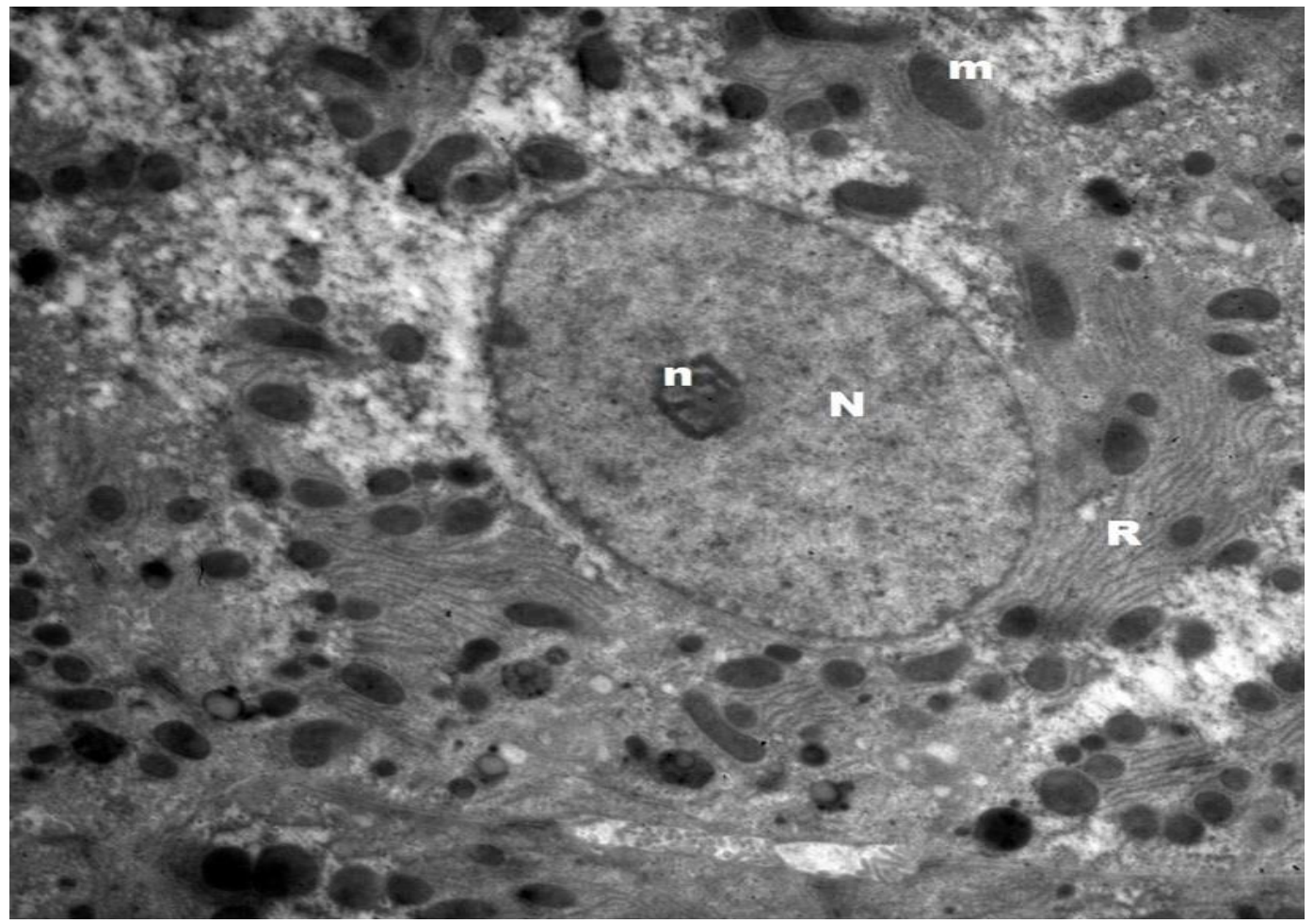

Figure (5): An electron micrograph from the control liver showing hepatocytes with euchromatic nucleus $(\mathrm{N})$, prominent nucleolus $(\mathrm{n})$, many mitochondria $(\mathrm{m})$, and rough endoplasmic reticulum $(\mathrm{R})$.

(TEM X 6000)

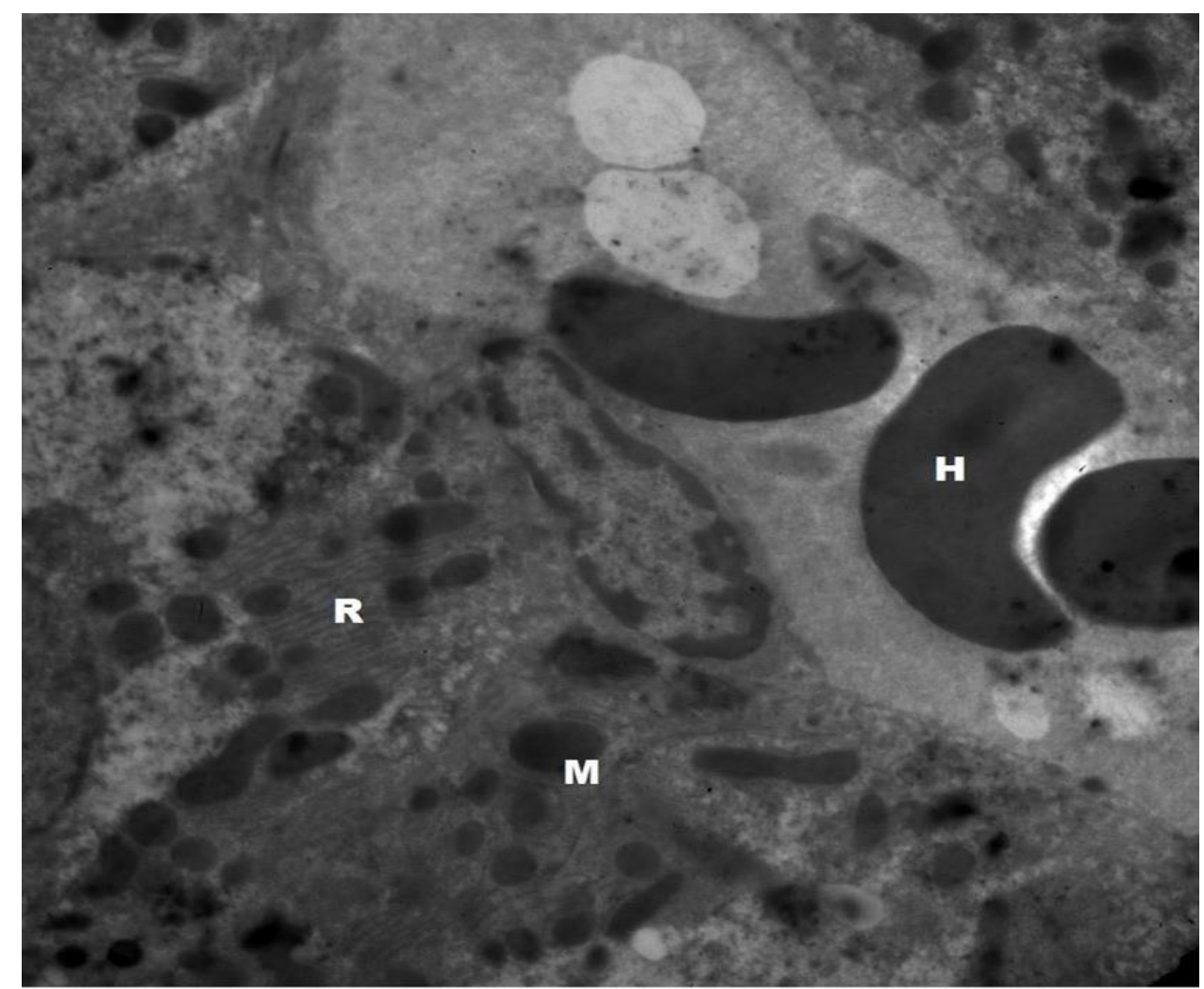

Figure (6): An electron micrograph from the liver of dimethate treated group showing cytoplasm of hepatocyte with electron dense nucleus, hemorrhge $(\mathrm{H})$, rough endoplasmic reticulum( $\mathrm{R})$ and many mitochondria $(\mathrm{M})$.

$(\mathrm{TEM} \times 6000)$ 


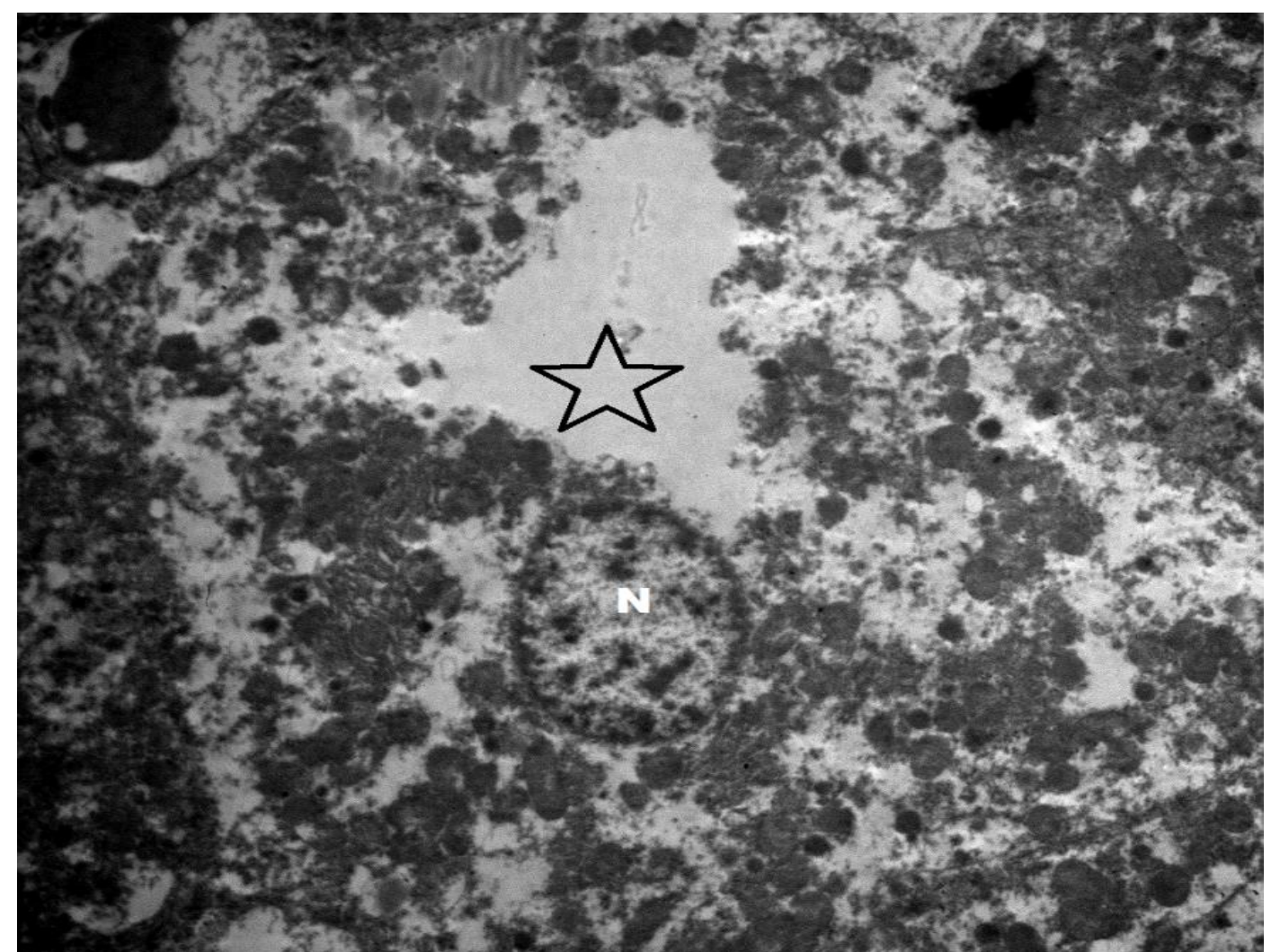

Figure (7): An electron micrograph from the liver of dimethate treated group showing Necrotic areas (star) and apoptotic nucleus (N).

$($ TEM $\times 6000)$

\section{DISCUSSION}

During the last decade, the extensive use of different pesticides in both agriculture

and public health purposes has led to drastic effects in many non-target species including man. One of these pesticides is the organophosphorus insecticide dimethoate which is used in housefly control and against a broad range of agricultural insect and mite pests (Srivastav et al., 2010).

Dimethoate inhibits the action of acetylcholinestrasein acute doses and it can cause different delayed symptoms from repeated or prolonged exposures (Costa, 2006).

The liver is the primary organ involved in metabolism and is a target organ of OPs and drugs. Hence in the present study hepatotoxicity of DM was studied. Clinical biochemistry and hispathological evaluations of liver are the used methods for detecting OP exposure effect (Crissman et al. 2004).

The results of the present study revealed that dimethoate treated group showed a highly significant increase in the level of alanin-aminotransferse (ALT) asparatatea-aminotransferase (AST) and the level of alkaline phosphatase (ALP) in the serum of Dimethoate treated group .

The results of this study coincide with Chatterjea and Shinde(2005); Attia and Nasr (2009); Salih (2010); Saafietal. (2011); AL-Awthan et al. (2012); El-Damaty et al. (2012) who recorded a marked increase in the level of alanin-aminotransferse (ALT) asparatatea-aminotransferase (AST) and the level of alkaline phosphatase (ALP) in the serum of Dimethoate treated group.

Penchalamma and Jacob Doss (2014) stated that the activities of ALT 
and AST in DM exposed rats showed statistically significant increased. Alteration in protein metabolic profiles was dose - and time- dependent.

Serum ALT and AST are considered to be among the mostsensitive markers for the diagnosis of hepatotoxicity (Kutlu et al., 2007 and Saafi et al., 2011).

According to Begum et al. (2007); Nagarjuna et al. (2008) ALT and AST are synthesis from amino acids. Repeated dose of DM hasa damaging effect on the cell metabolism leading to impaired protein synthesis.

Dewan et al. (2004); Ncibi et al. (2008) concluded that pesticide causes liver damage and leakage of cytosolic enzymes from hepatocytes and other body organs into the blood.

According to Friedman et al. (2003) elevation of liver enzymes may occur due to increased gene expression due to long term requirement of detoxification of pesticides.

The results of the present study revealed that dimethoate treated group showed that total protein and albumin levels were highly significant decreased in the serum of treated with Dimethoate as compared to control.

According to Attia and Nasr, (2009) there was decrease in serum total protien, albumin and globulin and increase in bilirubin level in dimethoate treated rats.

Dimethoate administration resulted in a significant decrease in serum total protien, albumin and globulin. The reduction in serum protein, particularly albumin, could be due tothe changes in protein and free amino acid metabolism and their synthesis in the liver. Also, the protein level suppression may be due to loss of protein either by reduce in protein synthesis or increased proteolytic activity or degradation. In addition, the observed decrease in serum proteins may be due to the damaging effect of dimethoate on liver cells, as confirmed by the increase in activities of serum AST and ALT (Yeragi et al., 2003).

A decrease in globulin is expected as globulin (mostly ã-globulins) could be consumed in the production of antibodies in response to dimethoate exposure (Institoris, et al., 1999).

The change in serum bilirubin which is considered as indicator of liver function may provide further evidence on dimethoate induced hepatotoxicity (Saafi et al., 2011 and Khan et al., 2013)

The results of the study revealed that Macroscopic examination of the liver of all the studied groups revealed normal appearance with no significant changes in size or abnormal masses compared with the control groups. Cut sections were apparently normal. While light Microscopic examination of the liver specimens of the rats revealed the following:

The light microscopic examination of the liver sections in the control untreated group showed a normal histological picture. The central vein lies at the centre of the lobule surrounded by the hepatocytes with strongly eosinophilic granulated cytoplasm, and distinct nuclei. While the liver of mice treated with dimethoate showed congestion portal vien,dilated bile duct, Hepatocytes with vacuolated cytoplasm and deeply stained skrunken nucleiandhemorrhage.

Electron microscopic examination of the control group showed hepatocytes appeared with euchromatic nuclei containing prominent nucleoli. The cytoplasm contained numerous 
mitochondria, rough endoplasmic reticulum. While dimethoate treated group showed areas of hemorrhage, apoptotic nucleus and necrotic areas.

These results are agreement with many authors; Selmanoglu and Akay (2000) who reported similar histopathological changes including mononuclear cell infiltration, congestion, hydropic degeneration and hepatocellular damage in the liver of male rats treated with dimethoate, endosulfan and carbaryl.

Also, Sharma et al. (2005) whofound that a 30-day exposure of male rats to technical grade dimethoate at doses of 6 and $30 \mathrm{mg} / \mathrm{kg}$ caused portal inflammation, centrizonal congestion and focal hepatocyte necrosis in the liver of rats .

Sayim, (2007); Gokcimenet al., (2007) and Elhalwagyet al.,(2008) Suggested that may occur hemorrhage, inflammatory cell infiltration.

In conclusion, in the present experiment sub-chronic dimethoate exposure in adult rats induced hepatotoxicity proved by both biochemical and histopathological changes.

It is recommended, to decrease use of pesticide in our environment and replace most of them by more safe natural material. Also continuous studies needed for evaluation the toxicity of pesticide and role of antioxidant in protection from its toxic effect.

\section{REFERENCES}

Al-Awthan, Y.S.; Al-Douis, MA.; ElSokkary, G.H. and Aqlan, E.M. (2012): Dimethoate-induced Oxidative Stress and Morphological Changes in the Liver of Guinea Pig and the
Protective Effect of Vitamin C and E. Asian Journal of Biological Sciences, 5(1):9-19.

Attia, A.M. and Nasr, H.M. (2009): Dimethoate-induced changes in biochemical parameters of experimental rat serum and its neutralization by black seed (Nigella sativa L.) oil. Slovak Journal of Animal Science, 42(2): 87-94.

Begum, G. (2007): Cypermethrin induced biochemical perturbations in freshwater fish Clariasbatrachus at sublethal exposure and after released into freshwater. Drug and Chemical Toxicology, 30:55-65.

Betrosian, A.; Balla, M.; Kafiri, G.;Kofinas, G.; Makri, R. and Kakouri A. (1995): Multiple system organ failure from organophosphate poisoning. J. Clin. Toxicol., 33 (3):257-260.

Chatterjea, M.N. and Shinde, R. (2005): Text Book of Medical Biochemistry. $6^{\text {th }}$ ed. Jaypee Broth. New-Delhi, P: 644.

Costa, L.G. (2006): Current issues in organophosphate toxicology. Clin. Chim. Acta., 366 (1-2):1-13.

Crissman, J.W.; Goodman, D.G.; Hildebrandt, P.K.; Maronpot, R.R.; Prater, D.A., and Riley J.H. (2004): Best practice guideline: toxicologic histopathology. Toxicol. Pathol., 32: 126-131.

Desi, I.; Nagymajteny, L.; Papp, A.and Schulz, H. (1998): Experimental model studies of pesticide exposure. Neurotoxicology, 19 (4-5), 611616.

Dreher, D.M. (2001a): Iso-dimethoate: acute oral toxicity in the rat: acute toxic class method. Safepharm Laboratories Limited. DTF Doc 
No: '463-004. [CHA; sub: 12564, Ref: 3-36/Vol 3-21].

Dreher, D.M. (2001b): Dimethoate $400 \mathrm{~g} / \mathrm{L}$ EC, stabilized. Acute Dermal Toxicity (Limit Test) in the rat. [CHA; sub: 12564, Ref: 386/Vol 3-41].

Dreher, D.M. (2001c): Dimethoate 400 g/L EC, stabilized. Acute dermal irritation in the rabbit. [CHA; sub: 12564, Ref: 3-87/Vol 3-41].

El-Damaty, E.M.A.; Farrag, A.H.; Rowayshed, G. and Fahmy, H.M. (2012): Biochemical and Histopathological Effects of Systemic Pesticides on Some Functional Organs of Male Albino Rats. Journal of Applied Sciences Research, 8(11):5459-5469.

Elhalwagy, M.E.A.; Darwish,N.S. and Zaher, E.M.(2008):Prophylactic effect of green tea polyphenols against liver and kidney injury induced by Fenitrothion

insecticide.pestic.Biochem.Phys.,91 : 81-89.

Farag, AT.; Karkour, TA.and ElOkazy, A. (2006): Developmental toxicity of orally administered technical dimethoate in rats. Birth Defects Res B Dev Reprod Toxicol., 77(1):40-46.

Gokcimen, A.; Gulle, K.; Demirin, H.; Bayram, D.; Kocak, A. and Altuntas,I. (2007):Effect of diazinon at different doses on rat liver and pancreas tissues. Pesticide Biochem.Physiol., 87:103-108.

Gomes, J.; Dawodu, A.; H.Lioyd, O.; Revitt, D.M. and Anilal S.V. (1999): Hepatic injury and disturbed amino acids metabolism in mice following to prolonged exposure to organophosphorus
pesticides.Hum. Exp. Toxicol., 18 (1):33-37.

Goodhew, P.J; Humphreys, J. and Beanland, R. (2003): Electron microscopey and analysis .In: Taylor and Francis. $4^{\text {th }}$ ed. London,New York.

Gore, A.C., (2001): Environmental toxicant effects on neuroendocrine function. Endocrine, 14: 235-246.

Hagar, H. and Fahmy A. (2002): A biochemical, histological, and ultrastructural evaluation of the effect of Dimethoate intoxication on rats pancreas. Toxicol.Lett., 133:161-170.

Hayes, W.J. and Laws, E.R. (1990): Handbook of Pesticide Toxicology, heavy metals in rats. Hum. Exp. Toxicol., 18(2):88-94.

Horobin, R.W. and Bancroft, J.D. (1998): Hematoxylin and eosin as an oversight stain. In: Trubleshooting Histology stains, $1^{\text {st }}$ ed., Churchill Livingstone Press, San Francisco, pp. 88- 93.

Institoris, 1.; Siroki, O.; Desi, 1. and Undeger, u. (1999): Examination of repeated dose combined exposure by dimethoate and twoheavy metals in rats. Hum. Exp. Toxicol., 18(2):88-94

Kamath, V. and Rajini, P.S. (2007): Altered glucose homeostasis and oxidative impairment in pancreas of rats subjected to dimethoate intoxication. Toxicology, 231(23):137-146.

Kamath, V.; Joshi, A.K.R. and Rajini, P.S. (2008): Dimethoate induced biochemical perturbations in rat pancreas and its attenuation by cashew nut skin extract. Pesticide Biochemistry and Physiology, 90(1):58-65. 
Khan, A.A.; Shah, M.A. and Rahman, S.U. (2013): Occupational Exposure to Pesticides and Its Effects on Health Status of Workers in Swat. Journal of Biology and Life Science, 4(2).

Kossmann, S.; Magner-Krezel. Z.; Sobieraj, R.andSzwed Z. (1997): The assessment of nephrotoxic effect based on the determination of the activity of some selected enzymes in urine. Przegel. Lek., 54 (10):707-711.

Lengyl, Z.; Fazakas, Z. and Nagymajteny L. (2005): Change in the central nervous activity of rats treated with Dimethoate in combination with other neurotoxicants in different phases of ontogenesis.m Arh. Hig. Rada. Toxicol., 56: 257-264.

Meister, R.T. (1992): Farm chemicals handbook. Willoughby, $\mathrm{OH}$ : Meister Publishing Company. Willoghby, $\mathrm{OH}$.

Mirajkar N. and Pope C.N. (2005): Dimethoate. Encyclopedia of Toxiocology, pp. 47-49

Nagarjuna, (2008): Effect of cypermethrin on hematological, protein metabolism and histological studies in albino rats. Ph.D. Thesis, Sri Venkateswara University, Tirupati, India.

Ogutcu, A.; Uzunhisarcikli, M.; Kalender, S.; Durak, D.; Bayrakdaa, F.and Kalender, Y. (2008): The effects of organophosphate insecticide diazinon on malondialdehyde levels and myocardial cells in rat heart tissue and protective role of vitamin E, Pest. Biochem. Physiol., 86(2): 93-98.

Pearlman, F.C. And Lee, R.T. (1974): Detecction and measurement of total bilirubin in serum, with use of surfactant as solubilizing agent. ClinChem., 20(4):447-453.

Penchalamma, R. and Doss,J.(2015): Alteration in Protein Metabolic Profiles in Liver Tissue of Rats during Dimethoate Toxicosis. I.O.S.R., 9: 30-33

Saafi, E.B.; Louedi, M.; Elfeki, A.; Zakhama, A.; Najjar, M.F.; Hammamia, M. and Achour, L. (2011): Protective effect of date palm fruit extract (Phoenix dactylifera L.) on dimethoate induced-oxidative stress in rat liver. Experimental and Toxicologic Pathology, 63(5):433.441.

Salih, E.M.A. (2010): Toxic Effect of Dimethoate and Diazinon on the Biochemical and Hematological Parameters in Male Rabbits. Jordan Journal of Biological Sciences, 3(2):77-82.

Sayim,F. ( 2007):Dimethoate induced biochemical and histopathology changes in the liver of rats.Exp.Toxicol.Pathol.,59:237243.

Senanayake, N. (1998): Organophosphorus insecticides poisoning.Ceylon.Med.J.43:22-29.

Sharma, Y.; Bashir, S.; Irshad, M.; Nagc, T.C. and Dogra, T. (2005): Dimethoate-induced effects on antioxidant status of liver and brain of rats following subchronic exposure. Toxicology, 215(2):173 181.

SPSS Inc (2013): SPSS for windows, version 22.0. Chicago, SPSS Inc. http://www.unimunester.de/imperia $/ \mathrm{md} /$ content/ziv/service/softwar e/spss/handbuecher/englisch/spss_b rief_guide_22.0.pdf.

Srivastav, A.K.; Mirshra, D.; Shrivastava, S.; Srivastav, S.K. 
and Srivastav A.K .(2010): Acute toxicity and behavioural responses of Heteropneustes fossilis to an organophosphate insecticide, dimethoate. Int. J. Pharma Bio Sci., 1: 359-363.

WHO/IPCS, (1996): Principles and methods for assessing direct immunotoxicity associated with exposure to chemicals. Environmental Health Criteria vol. 180. WHO, Geneva, 110- 112. 


\section{التسمم الكبدى بالدايمثيوات فى الجرذان المتعرضة للتسمم المزمن

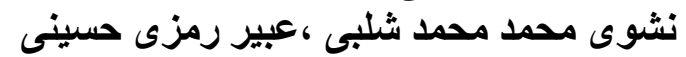

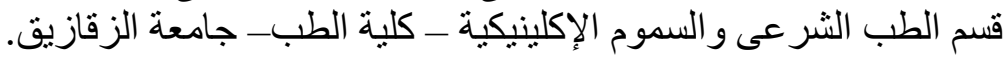

المقدمة:لان العربى المبيدات الحشرية تلعب دور هام فى الزراعة المعاصرة مع زيادة استخداماتها لذا فقد وجب

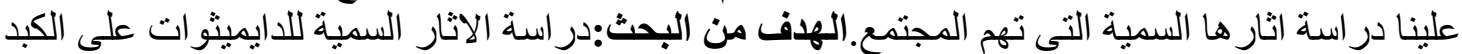

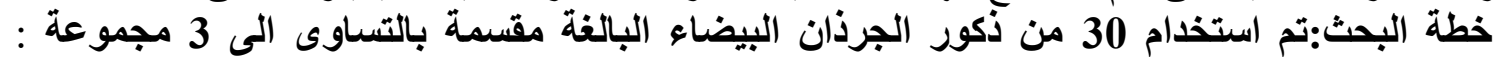

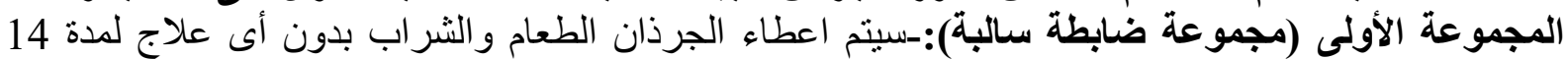

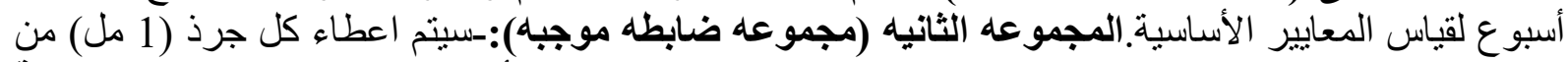

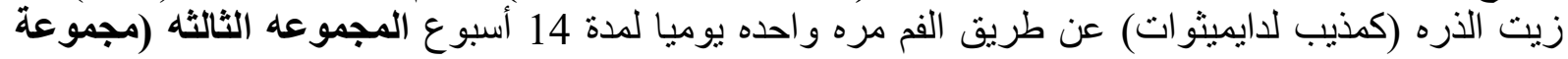

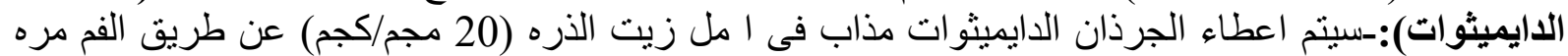

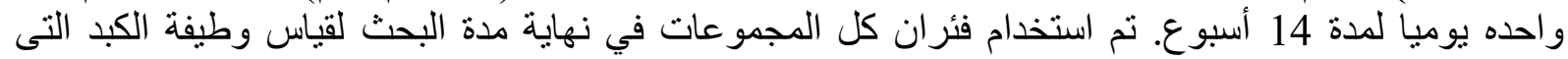

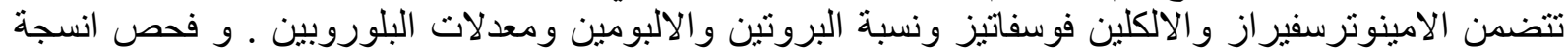

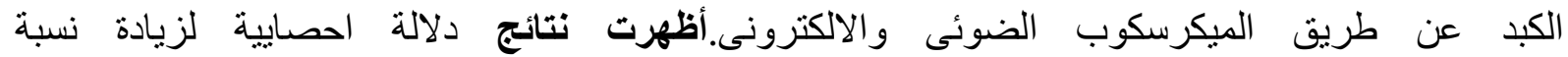

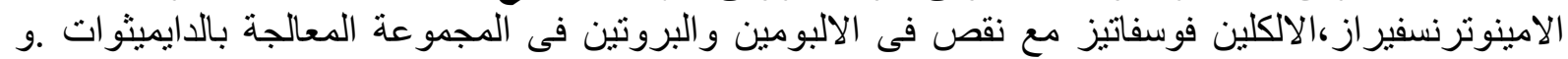

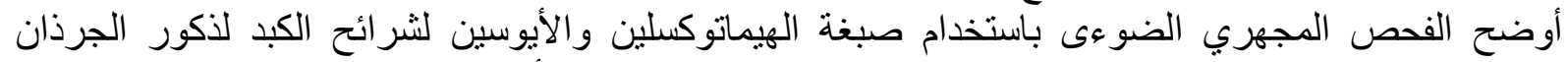

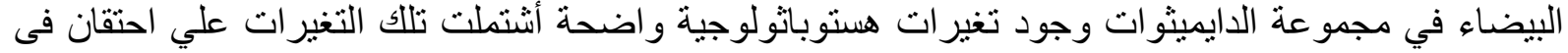

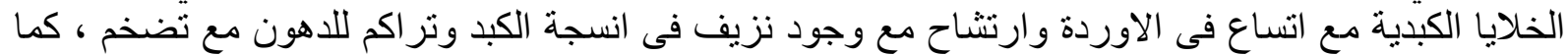

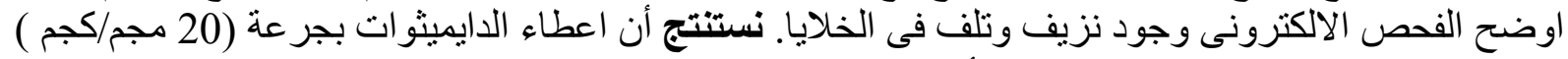

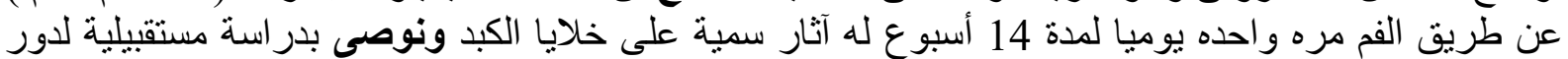

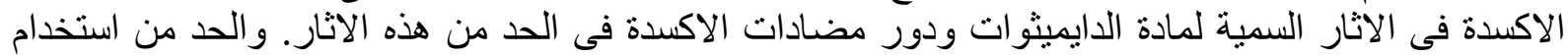

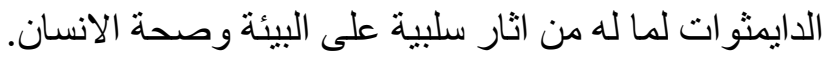

